\section{A Textbook of Clinical Pharmacology}

By H. J. Rogers, R. G. Spector and J. R. Trounce. Pp. viii +853 , illustrated. Hodder and Stoughton, London, 1981. $£ 12.95$.

If anyone wants to have a concise view of the metamorphosis that pharmacology has undergone in the past 30 years, with the enormous development of clinical pharmacology and pharmacokinetics, then this book will provide it admirably. It is a remarkable 3-author volume that covers all aspects of the subject in a succinct yet comprehensive way, building practical details of current therapeutic practice upon a foundation of clinical pharmacological science. A generous supply of illustrations of basic principles is taken from important references in the international literature, and this is therefore an excellent source of reference for research students as well as of authoritative information for the undergraduate medical student and prescribing doctor. In addition, it is remarkable value for money.

\section{Therapeutic Endoscopy and Radiology of the Gut}

Edited by John R. Bennetr. Pp. xii +271 , illustrated. Chapman and Hall, London, 1981. £20.00.
This an excellent book. For once, gastroenterologists have bothered to sit down and put into writing in some detail what they actually do in practice. This is no mean feat, as many of the techniques are complex. All the major gastroenterological techniques are described, clearly and in such a way that it should be possible to carry out the procedures by following the text. Because the book discusses no fewer than 16 different techniques in some 200 pages, clearly further reading will be required in some areas.

There is a fascinating chapter on the removal of foreign bodies with some excellent diagrams to illustrate the many ingenious techniques used for their removal. Whether 20 pages is rather too much to be devoted to this area, when virtually all foreign bodies are passed by themselves, is another question. The only serious criticism that I would have is that the illustrations in some of the chapters are very poor. This is partly due to the illustrations being in black and white. Photographs of upper gastrointestinal mucosal anatomy and pathology are never satisfactory in black and white. I hope that the next edition would have colour photographs where necessary.

Both the gastroenterologist and the radiologist will find this book invaluable. I will personally be using it a great deal in the course of my practice.

\title{
Notice
}

\section{The Nutrition Society}

The Nutrition Society will hold a meeting open to those interested in the nutritional aspect of clinical care on the subject of 'Assessment of Nutritional Status in Man'. The meeting will be held at the University of Sheffield on Tuesday and Wednesday, 20/21st April, 1982.

Topics will include-assessment of intake; assessment of body composition; assessment of energy requirements; immunological factors in nutritional assessment; anthropometry; biochemical aspect of nutritional assessment; plasma protein in nutritional assessment.

Original Communications, either 10 minute oral papers or as posters on the subject of the meeting will be considered by the Scientific Programmes Committee. Communications by non-members must be introduced by a member of The Nutrition Society. Further details can be obtained by writing to The Nutrition Society, Chandos House, 2 Queen Anne Street, London W1M 9LE. 